\title{
The social benefits of WEEE re-use schemes. A cost-benefit analysis for PCs in Spain.
}

Xose Manuel González*

Miguel Rodríguez*

Yolanda Pena-Boquete**

*University of Vigo

**Institute for Studies on the Mediterranean Societies (ISSM), Italian National Council of Reseatch (CNR)

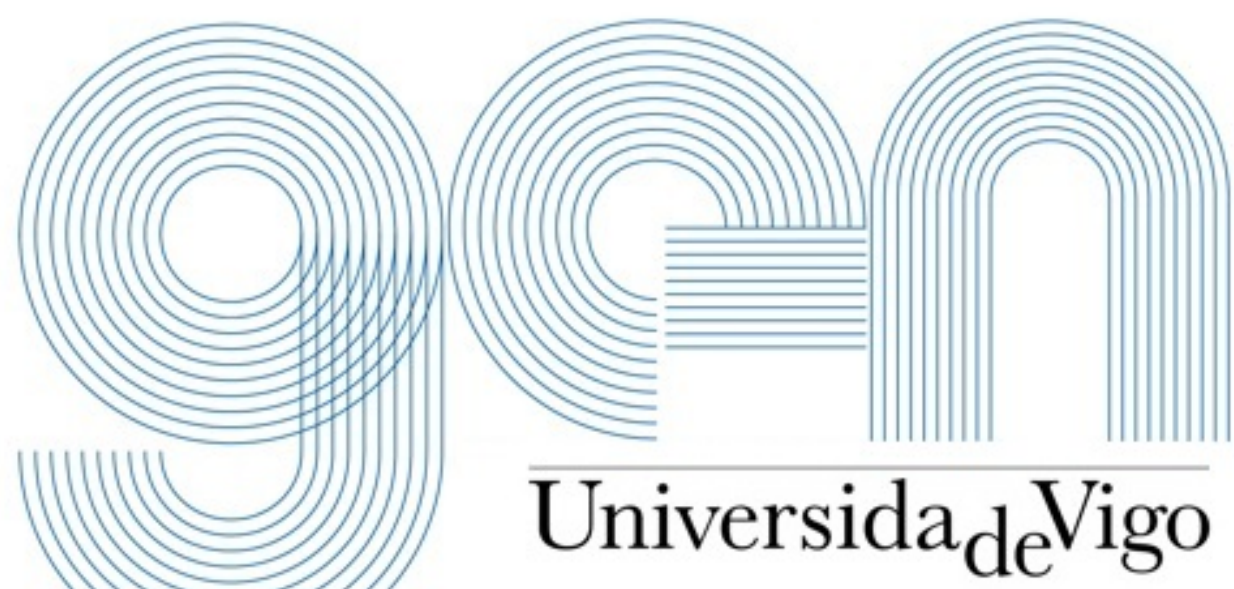




\title{
The social benefits of WEEE re-use schemes.
}

\section{A cost-benefit analysis for PCs in Spain.}

\author{
Xose Manuel González ${ }^{1}$, Miguel Rodríguez², Yolanda Pena-Boquete ${ }^{3}$.
}

\begin{abstract}
One goal of the new European legislation set out in WEEE Directive 2012/19 / UE is the promotion of WEEE re-use schemes. However, some authors are rather sceptical about the contribution of WEEE re-use schemes to improve resource efficiency. The main contribution of this paper is to enlarge the empirical literature by providing a cost-benefit analysis (CBA) of re-use schemes versus recycling processes of PCs in Spain, evaluating the abatement of environmental impacts. Following recommendations of some authors, this should be a compulsory first step to design adequate policy instruments. Our results suggest that promoting re-use against recycling may reduce environmental costs by 45.20€ per PC. These results provide valuable information to policy makers and think tanks willing to design supporting schemes for re-use over recycling operations.
\end{abstract}

Keywords: WEEE, re-use schemes, externalities, cost benefit analysis.

\footnotetext{
${ }^{1}$ Universidade de Vigo, Facultade Económicas e Empresariais, 36310 Vigo, Spain.

${ }^{2}$ Universidade de Vigo, Facultade Empresariais e Turismo, 32004 Ourense, Spain.

${ }^{3}$ Institute for Studies on the Mediterranean Societies (ISSM), Italian National Council of Research (CNR), Via Guglielmo Sanfelice 8, 80134 Naples, Italy.

1xmgonzalez@uvigo.es; ${ }^{2}$ miguel.r@uvigo.es (corresponding author); ${ }^{3}$ y.penaboquete@issm.cnr.it;
} 


\section{Introduction}

Waste of electrical and electronic equipment (WEEE) such as computers, televisions, refrigerators, and cell phones globally represent the widest source of waste (Afroz et al., 2013), and it is one of the fastest growing waste streams in the EU. There are environmental, economic, and social benefits calling for the proper management of WEEE. First, it may abate environmental and health problems associated with hazardous substances. Second, the recycling process may deliver scarce and valuable materials for the economy and reduce the environmental burdens associated with the consumption of primary new materials (Cucchiella et al., 2015). Finally, the recycling process may provide ancillary social benefits like social inclusion opportunities in different ways: employment for disabled people or the long-term unemployed, helping to bridge the digital divide, etc. (Kissling et al, 2012). Accordingly, "there is a need to move from the linear model produce, consume, throw to a circular economy, where nothing is wasted, everything is transformed" (Seyring et al., 2015).

In order to address these problems, a new European legislation (the WEEE Directive 2012/19/EU) became effective in 2014. The intention of the European Commission was to tackle the fast increasing WEEE waste stream by passing more stringent legislation than the first WEEE Directive (Directive 2002/96/EC). This legislation should contribute to the circular economy and enhance resource efficiency. This legislation places preparation for re-use at the top of the hierarchy because "it ensures the product recovers its maximum potential, with a minimum use of resources” (Seyring et al., 2015). Despite the European Parliament goal of a separate 5\% re-use target, the new WEEE Directive (2012/19/EU) lacks specific targets for re-use because of the resistance by the European Council of Ministers. More recently, the European Commission adopted an ambitious Circular Economy Package (COM(2015) 614/2), which includes revised 
legislative proposals on waste that should provide strong incentives and concrete measures to boost re-use activities but again without specific targets. Consequently, key stakeholders under the current law (e.g., member states, collective schemes for WEEE) may have weak incentives for prioritizing preparation for re-use schemes over recycling operations. Accordingly, “the option of preparing for re-use might be neglected”, which may explain that only $2 \%$ of WEEE collected in the EU28 were re-used or subject to preparation for re-use processes in 2012 (Seyring et al., 2015). We could expect the same situation in the near future until the approval of specific targets for re-use.

In the particular case of small IT and telecommunications equipment, the progressive shortening of product's end-of-life for some consumers (i.e., medium-/high-income households, large financial and industrial corporations) represents an increasing pressure on resources and quantities of e-waste that must be dealt with. Re-use activities may support greater economic and ecological efficiency by extending the use phase of products and reducing the manufacturing of new ones. To that end, the re-use sector should operationalize adequate logistical arrangements to accommodate the different life spans of products among potential users. For instance, the life span of personal computers (PCs) is usually shorter for large corporations than households. Accordingly, households, and many other final consumers like educational and non-profit institutions, could be the recipients of discarded products from large corporations where there is an increasing prevalence of lease-based models (Intlekofer et al., 2010). Following this line of reasoning, Williams et al. (2008) affirm "increases in reuse significantly lower net environmental impacts”, but the literature lacks proper empirical analysis to provide evidence for this statement. In the same vein, Truttmann and Rechberger (2006) claim "measures taken to promote reuse should be evaluated by cost-benefit analysis in comparison to measures that enhance the effectivity of collection and recycling”. Our 
survey of the empirical literature has provided us several studies performing life cycle analyses (LCAs) for PCs, such as Choi et al. (2006), Duan et al. (2009), Andrae and Andersen (2010), and Yao et al. (2010). We also may found papers that included data about recycling processes, such as Sepúlveda et al. (2010), Hischier et al. (2005), Cui and Forssberg (2003), Wang and Xu (2014), Kolias et al. (2014), and Manikpura et al. (2014). However, we were unable to find references that compare recycling with re-use processes of PCs by quantifying the environmental impact avoided, in physical and monetary terms.

Accordingly, the main objective of this paper is to enlarge the empirical literature by providing a cost-benefit analysis (CBA) of re-use schemes versus recycling processes of PCs in Spain ${ }^{1}$. The main contribution of the paper is to identify re-use schemes delivering greater resource and economic efficiency, hence improving welfare. To that end, the paper develops a CBA beyond a technical analysis based on LCA, which is a compulsory first step to design adequate policy instruments. The results may provide valuable information to policy makers and think thanks to design supporting schemes for re-use over recycling operations.

The paper includes the following sections. Section 2 will provide the necessary background and the scope of the paper. This section will summarise the environmental impact of preparation for re-use versus recycling for the demonstration processes covered by the project. In Section 3, we present the methodology and database. Section 4 presents the results and discussion of empirical findings. Finally, section 5 summarizes conclusions and the main policy implications.

\footnotetext{
${ }^{1}$ The CBA is part of a broader research agenda: the ecoRaee Project. It is a LIFE+ project funded by the EU that aims to characterize the industrial processes of preparation for PCs re-use. Thus, results from the LCA analysis published by ecoRaee represent the background for this CBA.
} 


\section{Background}

According to Kissling et al. (2012), preparing for re-use may "optimize the use phase of a product in order to achieve greater resource efficiency". In doing so, these authors argue that re-use activities do not "compete with recycling as an end of life solution” but only postpone the definite end of life by extending the use phase of products. Hence, preparation for re-use is usually previous to recycling in the waste management hierarchy ${ }^{2}$ in national legislations because it reduces the consumption of resources (materials and energy) during the manufacturing of new appliances. However, new products are usually more energy efficient. Therefore, "there is a trade-off between resource conservation in the production phase and energy consumption during the use phase making reuse not a priori a goal-oriented option” (Truttmann and Rechberger, 2006). These authors are rather sceptical about the contribution of WEEE re-use schemes to improve resource efficiency. They argue that policy makers' efforts should concentrate on improvements of collection and recycling processes because that will deliver better outcomes.

The conclusions reached by Truttmann and Rechberger (2006) may be one of the reasons for the resistance by the European Council of Ministers to set up any specific re-use target in the 2012 EU legislation. Furthermore, Kissling et al. (2012) maintain that the opposition to set up specific re-use targets by the European Council of Ministers may be related to the difficulty to "identify policy instruments that can be used to do so [greater levels of re-use] without the risk of creating expensive systems with the potential for inefficient outcomes”. In addition, a recent study conducted by Seyring et al. (2015), on behalf of the European Commission, assessed the implementation of separate re-use

\footnotetext{
${ }^{2}$ For instance, the European Union waste legislation (Directive 2008/98/EC) states: “The following waste hierarchy shall apply as a priority order in waste prevention and management legislation and policy: prevention, preparing for re-use, recycling, other recovery (e.g. energy recovery) and disposal”.
} 
targets within the new Circular Economy Package. That study recommended against the inclusion of re-use targets because of limitations on databases "for assessing the feasibility of such targets accompanied by only limited benefits compared to a further enforcement of selective treatment and increasing collection rates”.

For the particular case of personal computers, Kissling et al. (2012) provide the more interesting analysis to our knowledge. The aim of their study is to identify re-use operating models exhibiting positive potential for re-use. As a result, they provide a useful generic typology of the re-use industry for desktop and notebook computers: 1) the IT Asset Management Model, 2) the Close the Digital Divide Model, 3) the Social Enterprise Model. The first business model supplies re-use computers "for miscellaneous large corporate users”. The other two represent non-profit operating models that differ in their customer segments. Close the Digital Divide organizations supply re-use computers “at low prices to eligible institutional recipients in developing countries”, whereas Social Enterprises re-sell them "through charity outlets directly to individual users or to eligible institutional users such as schools or health organisations” (the main objective of Social Enterprises is to create employment and education opportunities). Unfortunately, the potential for re-use analysis of the operating models in Kissling et al. (2012) lacks a complete analysis of the environmental, social, and economic impacts.

Additionally, Kissling et al. (2013) identified the generic success factors and barriers faced by the re-use industry. Among the success factors, quality of re-use products delivered by preparation for re-use processes is ranked by far the most important element in the value chain. On the other hand, the top barrier involves access to sufficient volumes of WEEE with re-use potential. The extent of informal-illegal practices and the variance and complexity in regulations (leading to administrative costs) also represent important barriers. Ongondo et al. (2013) provide a similar analysis focused on the Social Enterprise 
Model. Their findings suggest that most barriers are related to marketing and legislative issues.

Finally, Babbitt et al. (2009, 2011) characterize the flow of end-of-life appliances (quantity, value, and disposition) at a major U.S. educational institution. Their study included desktop and laptop computers sold either for refurbishing-resale (averaged U.S. \$20-100 per unit) and directly to individuals for re-use (reaching \$250-350 per unit). They describe the economic and equipment flow from re-use of personal computers, but their study lacks a complete CBA.

\subsection{The ecoRaee project}

This paper is framed within a larger project, ecoRaee ${ }^{3}$, which is the acronym for the EU LIFE+ project, Demonstration of a re-use process of WEEE addressed to propose regulatory policies in accordance to EU law. One of the objectives of the project is to characterize the potential for re-use of different operating models according to "the ecologic, economic and social advantageousness of re-use compared to direct product recycling and disposal” (Kissling et al, 2012). According to these authors, the economic dimension of the "potential for re-use" relates to the fact that it should be "financially viable, i.e. capable to generate a stable income through the sale of products and services or through other income streams such as public or private donations, which enable it to properly perform and develop its operations in the long term”.

The ecoRaee project developed four demonstration processes to analyse the feasibility of industrial preparation processes for re-use of conventional computers. The ecoRaee project typifies a conventional computer with the following characteristics: a PC Intel

\footnotetext{
${ }^{3}$ For more information on the project visit the web page: http://www.life-ecoraee.eu/en/.
} 
Pentium IV, 2 GHz, 40 GB HDD, CD-ROM unit, 512 MB RAM, screen (CRT or LCD), keyboard, and optical mouse. It was assumed that the initial PC was manufactured in Asia. It was also assumed that the use phases, the preparation for re-use processes, and recycling take place in Spain in compliance with the principle of proximity (local or regional level). The four demonstration processes comprise: the production and operation of a Central Data Acquisition and Control Unit for air conditioning and lighting control system (Demo I: CDACU); a Cluster of computers for grid processing (Demo II: CLUSTER); a Perimeter Security Device Intranet (Demo III: PSDI); and a general Purpose Computer (Demo IV: PC).

\section{Methodology and data}

As mentioned, the objective of this paper is to assess the welfare gains derived from a public regulation aimed to reduce WEEE externalities. Specifically, the proposal submitted to assessment is the implementation of the WEEE Directive (2012/19/EU) on the PC market in Spain. The transposition of the directive in Spain has included a minimum re-use target of $5 \%$.

The assessment methodology used in this paper is the CBA, which allows us to assess whether the society wins or loses when we encourage re-use schemes instead of recycling. Avoided environmental impacts may be used as an indicator of improved welfare. However, a proper evaluation of welfare gains requires not only the quantification of avoided externalities in physical units but also their monetary valuation. In the field of public economics, the CBA is an important tool for decision-making since it seeks to assess the appropriateness of a regulation or a project by the identification of all costs and 
benefits directly and indirectly linked to the regulation or project, and subsequently their valuation in monetary terms (Pearce et al., 2006; Hanley, 2001).

\subsection{Quantification of Externalities in physical units from LCA}

As we have pointed out, the ecoRaee project carried out an LCA of a PC, tracking it "from the cradle to the grave" to quantify its environmental impact. To that end, the ecoRaee project followed the 2008 methodology (Goedkoop et al., 2013) with the SimaPro LCA software. This methodology converts emissions of hazardous substances and extraction of exhaustible natural resources in 18 environmental impact categories. ${ }^{4}$

The CBA in this paper is provided only for the Demo IV (a general purpose computer) because it delivers a positive outcome for both the $\mathrm{LCA}^{5}$ and the business model (it shows positive returns for firms providing preparation for re-use services and it displays the greater market potential). Accordingly, this section presents the LCA for the Demo IV only.

The time horizon of this LCA included the first stage of the useful life of a standard PC made from raw materials (5 years) and a second stage of 2 years for two alternative scenarios (re-use and recycling), as Figure 1 illustrates. Computers in both scenarios have been defined under the same requirements regarding issues of functionality and scope, so that they are equivalent in the two scenarios.

\footnotetext{
${ }^{4}$ The 18 impact categories addressed at the midpoint level are the following: climate change, ozone depletion, terrestrial acidification, freshwater eutrophication, marine eutrophication, human toxicity, photochemical oxidant formation, particulate matter formation, terrestrial ecotoxicity, freshwater ecotoxicity, marine ecotoxicity, ionising radiation, agricultural land occupation, urban land occupation, natural land transformation, water depletion, mineral resource depletion, and fossil fuel depletion.

${ }^{5}$ The methodology section in this paper presents a summary of results because the full coverage of the LCA is beyond the scope of this paper. For full details on this issue, please visit the project Web page and deliverables available online.
} 
Figure 1. System limits in the LCA within the ecoRaee Project.

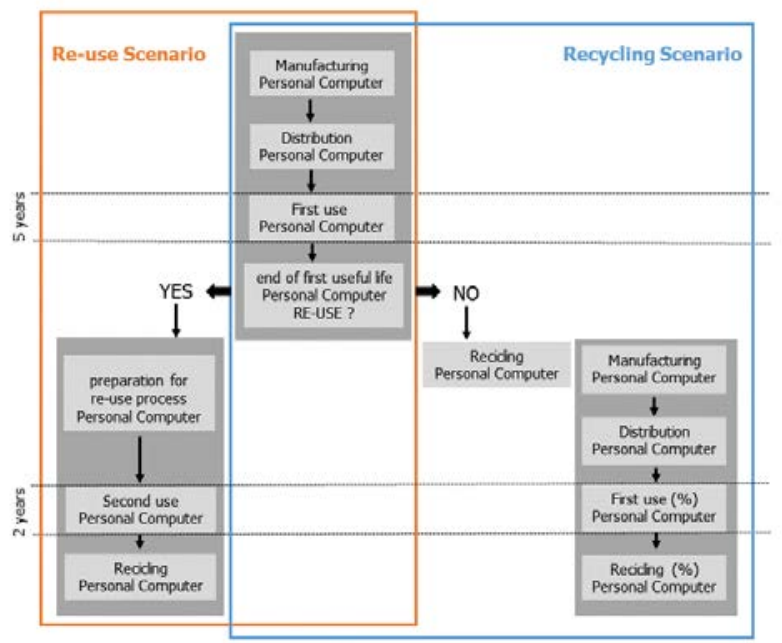

Source: provided by EnergyLab for the ecoRaee Project.

Re-use Scenario: The first stage of its useful life of 5 years starts with a PC manufactured from raw materials, then it follows the distribution phase, and finally the use phase, which includes the consumption of electricity. The second stage of the useful life, which lasts two years, comprises the re-use preparation process to obtain a functional unit and finally the use phase of the re-use equipment, where its energy consumption is evaluated. At the end of this second life, the re-used product is shipped to recycling.

Recycling Scenario: As in the previous scenario, the first stage includes manufacturing, distribution, and use of a PC made with raw materials. However, after this 5-year stage, the standard computer is recycled (it does not undergo a re-use preparation process). Thus, in order to meet the time frame as in the re-use scenario (2 additional years), it is necessary to resort to new equipment providing the same functions as the product obtained in the re-use preparation process (including manufacturing, distribution, and electricity consumed by this device). Again, at the end of its life, this product is shipped to recycling. Therefore, the first stage of the life cycle (production, distribution, and use of equipment during the first 5 years) is equivalent in both scenarios, so there is no need for this stage 
to be analysed by the LCA. All differences between the two scenarios occur in the second stage. As displayed in Table 1, the re-use scenario (scenario A) generates fewer physical units of environmental impact than the recycling scenario (scenario B) in all categories except one (occupation of agricultural land). In other words, the comparison of the re-use versus the recycling through the LCA presents a negative sign (low impact) in 17 categories. Therefore, the initial hypothesis stated in Williams et al. (2008) is confirmed: re-used products (taking into account the process of preparation for re-use and subsequent distribution to recipients) present lower environmental impacts than the manufacturing and distribution of new products from raw materials.

The lower impact exhibited by the re-use scenario (scenario A) is mainly generated in the re-use preparation process and distribution activities. The difference in the distribution stage during the second life cycle originates from the fact that the ready to re-use product is done locally, while the brand new product is manufactured in Asia. On the other hand, as expected, the re-use scenario displays a worse performance in energy consumption and quantity of material sent to recycling, but that underperformance is offset by the lower impact on the stages of manufacture and distribution of PCs.

The lower impact of the re-use scenario generates a clear social benefit in the form of better environmental conditions, healthier environments, avoided diseases, most protected natural resources, etc. These social benefits can be quantified in monetary terms, and this issue will be addressed in the next section. 
Table 1: Environmental impacts from Re-use (A) and Recycling (B) by LCA.

\begin{tabular}{|c|c|c|c|c|c|}
\hline Impact category & & $\begin{array}{l}\text { Reuse process } \\
\text { /Manufacturing }\end{array}$ & Distribution & $\begin{array}{c}\text { Energy } \\
\text { onsumption }\end{array}$ & $\begin{array}{c}\text { Recycling } \\
\text { GRFA }\end{array}$ \\
\hline Climate change & Scenario A & 17,0285 & 13,9353 & 151,6629 & $-26,7611$ \\
\hline kg CO2 eq & Scenario B & 212,5411 & 83,4711 & 81,0172 & $-30,2089$ \\
\hline Ozone depletion & Scenario A & 2,41E-06 & 1,98E-06 & $1,16 \mathrm{E}-05$ & $3,96 \mathrm{E}-07$ \\
\hline kg CFC-11 eq & Scenario B & $1,73 \mathrm{E}-05$ & $1,06 \mathrm{E}-05$ & $6,18 \mathrm{E}-06$ & 4,82E-07 \\
\hline Human toxicity & Scenario A & 2,3388 & 3,7242 & 66,1412 & 30,3714 \\
\hline kg 1,4-DB eq & Scenario B & 643,0519 & 3,6713 & 35,3321 & 42,8581 \\
\hline Photochemical oxidant for. & Scenario A & 0,1059 & 0,0849 & 0,5490 & $-0,2063$ \\
\hline kg NMVOC & Scenario B & 0,8648 & 0,4262 & 0,2933 & $-0,2593$ \\
\hline Particulate matter formation & Scenario A & 0,0300 & 0,0250 & 0,3170 & $-0,0609$ \\
\hline kg PM10 eq & Scenario B & 0,4751 & 0,1101 & 0,1693 & $-0,0797$ \\
\hline Ionising radiation & Scenario A & 3,5670 & 2,9719 & 115,4845 & 4,2666 \\
\hline kg U235 eq & Scenario B & 61,0932 & 2,8306 & 61,6910 & 5,4943 \\
\hline Terrestrial acidification & Scenario A & 0,0628 & 0,0530 & 0,9889 & $-0,1100$ \\
\hline kg SO2 eq & Scenario B & 1,4064 & 0,3206 & 0,5283 & $-0,1401$ \\
\hline Freshwater eutrophication & Scenario A & 0,0022 & 0,0029 & 0,0573 & $-0,0030$ \\
\hline kg P eq & Scenario B & 0,4165 & 0,0027 & 0,0306 & $-0,0039$ \\
\hline Marine eutrophication & Scenario A & 0,0035 & 0,0029 & 0,0310 & $-0,0017$ \\
\hline kg N eq & Scenario B & 0,3644 & 0,0150 & 0,0166 & $-0,0028$ \\
\hline Terrestrial ecotoxicity & Scenario A & 0,0027 & 0,0021 & 0,0352 & 0,0280 \\
\hline kg 1,4-DB eq & Scenario B & 0,0445 & 0,0078 & 0,0188 & 0,0394 \\
\hline Freshwater ecotoxicity & Scenario A & 0,0612 & 0,0725 & 1,0240 & 3,3475 \\
\hline kg 1,4-DB eq & Scenario B & 8,7660 & 0,0826 & 0,5470 & 4,4958 \\
\hline Marine ecotoxicity & Scenario A & 0,0718 & 0,0810 & 1,1041 & 2,0028 \\
\hline kg 1,4-DB eq & Scenario B & 8,4584 & 0,1060 & 0,5898 & 2,6036 \\
\hline Agricultural land occupation & Scenario A & 7,2634 & 0,0636 & 3,8815 & 0,3958 \\
\hline m2a & Scenario B & 8,7083 & 0,0800 & 2,0735 & 0,3952 \\
\hline Urban land occupation & Scenario A & 0,5507 & 0,3951 & 0,7088 & $-0,0106$ \\
\hline $\mathbf{m} 2 \mathbf{a}$ & Scenario B & 4,5014 & 0,2590 & 0,3787 & $-0,0206$ \\
\hline Natural land transformation & Scenario A & 0,0066 & 0,0048 & 0,0259 & 0,0002 \\
\hline $\mathbf{m} 2$ & Scenario B & 0,0370 & 0,0413 & 0,0138 & 0,0002 \\
\hline Water depletion & Scenario A & 0,0623 & 0,0527 & 1,1434 & $-0,1807$ \\
\hline m3 & Scenario B & 3,4184 & 0,1215 & 0,6108 & $-0,2315$ \\
\hline Metal depletion & Scenario A & 1,0894 & 1,2927 & 11,1381 & $-7,5448$ \\
\hline kg Fe eq & Scenario B & 170,4784 & 0,5351 & 5,9499 & $-10,2769$ \\
\hline Fossil depletion & Scenario A & 6,1890 & 4,9202 & 47,1080 & $-37,4335$ \\
\hline kg oil eq & Scenario B & 56,9326 & 29,0302 & 25,1648 & $-46,8486$ \\
\hline
\end{tabular}

Source: ecoRaee project. 


\subsection{Quantification of externalities in monetary units}

As mentioned, the CBA allows us to quantify the social benefits not just in physical units but also in monetary terms. However, environmental damages are not exchanged in markets; therefore, we are unable to observe their prices. Overcoming this problem requires the calculation of shadow prices, which allow us to impute theoretical values based on opportunity costs.

To calculate the shadow prices, we could use two methods: the abatement or the damage cost. The first method will assess the costs that society should assume to secure environmental policy targets. ${ }^{6}$ For instance, when a project that has to be evaluated leads to changes in the efforts required to secure environmental targets. Unfortunately, the abatement cost may not be used for other countries or regions different from the one they were originally calculated for, since the policy targets would be different.

The damage costs method is preferable when, for instance, a public project leads to changes in environmental quality. This is actually the case addressed in this paper because it evaluates the changes in environmental quality produced by re-use schemes versus recycling. People's willingness to pay (WTP) to avoid environment damages is based on damage cost methods. Unfortunately, the literature does not offer damage cost for all items in any country. The damage costs estimated in one country can be used in other countries or regions and from other temporal periods up to a certain point. However, some adjustments are necessary to use damage costs estimated for one country for environmental appraisal in other countries. That benefit transfer methodology will include the following adjustments:

\footnotetext{
${ }^{6}$ From an economic perspective, the abatement costs are equal to the Pigovian charge, which would have to be paid to achieve the set of political targets.
} 


\section{1) Territorial adjustments}

First, the monetary values have to be corrected in order to take into account spatial differences by using the exchange rate and the purchasing parity power (PPP). However, this simple adjustment for transfer values would not be enough for countries with very different income levels and costs of living. In this case, we should apply income adjustments in a second step. Thus, we calculate the WTP of the country $p$ based on the WTP of country $s$ as follows:

$$
W T P_{p}=W T P_{s}\left(Y_{p} / Y_{s}\right)^{\beta}
$$

Where the subscripts $s$ and $p$ indicate the original country of study (country where damages cost are calculated from primary data) and the policy country under analysis, $Y_{S}$ and $Y_{P}$ are the income levels, respectively, and $\beta$ is the income elasticity of the demand for the environmental good. The Shadow Prices Handbook indicates that "the income elasticity for various environmental goods is typically less than 1 and often in the 0.40.85 range”. It further indicates that an income elasticity of 0.85 has been used in the uplift factor for temporal adjustment of values due to economic growth within the NEEDS project. Note that, formally, ß is the income elasticity of WTP, not of demand, and there is no simple relationship between the two measures.

\section{2) Temporal adjustments}

In the short term, the shadow prices should be corrected for inflation by using the consumer price index. Additionally, in the long term, the damage costs should also be corrected for changes in income levels, as explained above. 


\subsection{Data Sources}

Table 2 below shows the data sources for each one of the 18 impact categories addressed in the LCA. The prices of the climate change, ozone depletion, human toxicity, photochemical oxidant formation, particulate matter formation, ionising radiation, terrestrial acidification, freshwater eutrophication, marine eutrophication, and land occupation were taken from the CE Delft (2010). The prices of the terrestrial ecotoxicity, freshwater ecotoxicity, and marine ecotoxicity were taken from van Harmelen, et al. (2007). Regarding metal depletion and fossil fuel depletion, both CE Delt (2010) and van Harmelen, et al. (2007) argue: "To the theme of abiotic resource depletion we have assigned a shadow price of zero. In properly functioning markets, future scarcity will be reflected in prices and there will be no externalities”. Finally, the prices of the metal depletion and fossil fuel depletion were taken from Goedkoop, et al. (2008). All of these values have been transferred to this Spanish study following the steps explained previously in the methodology section. The Eurostat provides the values for GDP, PPP, and consumer price indices. 
Table 2: Details of the primary data for valuing impact categories

\begin{tabular}{|c|c|c|c|c|}
\hline Impact category & Primary data & $\begin{array}{l}\text { Reference country } \\
\text { and year in the } \\
\text { primary data }\end{array}$ & $\begin{array}{l}\text { Methodology in the } \\
\text { primary data }\end{array}$ & Units \\
\hline Climate change & CE Delft (2010) & Netherlands - 2008 & Literature analysis & $€ / \mathrm{kg} \mathrm{CO} 2 \mathrm{eq}$ \\
\hline Ozone depletion & CE Delft (2010) & Netherlands - 2008 & ReCiPe + Literature & $€ / \mathrm{kg}$ CFC-11 eq \\
\hline Human toxicity & CE Delft (2010) & Netherlands - 2008 & NEEDS & $€ / \mathrm{kg} 1,4-\mathrm{DB}$ eq \\
\hline $\begin{array}{l}\text { Photochemical } \\
\text { oxidant formation }\end{array}$ & CE Delft (2010) & Netherlands - 2008 & NEEDS & $€ /$ kg NMVOC \\
\hline $\begin{array}{l}\text { Particulate } \\
\text { matter formation }\end{array}$ & CE Delft (2010) & Netherlands - 2008 & NEEDS & $€ /$ kg PM10 eq \\
\hline Ionising radiation & CE Delft (2010) & Netherlands - 2008 & NEEDS & $€ /$ kg U235 eq \\
\hline $\begin{array}{l}\text { Terrestrial } \\
\text { acidification }\end{array}$ & CE Delft (2010) & Netherlands - 2008 & NEEDS & $€ / \mathrm{kg} \mathrm{SO} 2 \mathrm{eq}$ \\
\hline $\begin{array}{l}\text { Freshwater } \\
\text { eutrophication }\end{array}$ & CE Delft (2010) & Netherlands - 2008 & ReCiPe & $€ / \mathrm{kg} P$ eq \\
\hline $\begin{array}{l}\text { Marine } \\
\text { eutrophication }\end{array}$ & CE Delft (2010) & Netherlands - 2008 & NEEDS & $€ / \mathrm{kg} \mathrm{N}$ eq \\
\hline $\begin{array}{l}\text { Terrestrial } \\
\text { ecotoxicity }\end{array}$ & $\begin{array}{l}\text { van Harmelen, } \\
\text { et al. (2007) }\end{array}$ & Netherlands - 2000 & NIBE Research (2002). & $€ /$ kg 1,4-DB eq \\
\hline $\begin{array}{l}\text { Freshwater } \\
\text { ecotoxicity }\end{array}$ & $\begin{array}{l}\text { van Harmelen, } \\
\text { et al. (2007) }\end{array}$ & Netherlands - 2000 & NIBE Research (2002). & $€ / \mathrm{kg} 1,4-\mathrm{DB}$ eq \\
\hline $\begin{array}{l}\text { Marine } \\
\text { ecotoxicity }\end{array}$ & $\begin{array}{l}\text { van Harmelen, } \\
\text { et al. (2007) }\end{array}$ & Netherlands - 2000 & NIBE Research (2002). & $€ /$ kg 1,4-DB eq \\
\hline $\begin{array}{l}\text { Agricultural land } \\
\text { occupation }\end{array}$ & CE Delft (2010) & Netherlands - 2008 & ReCiPe & $€ / \mathrm{m} 2$ \\
\hline Water depletion & $\begin{array}{l}\text { Goedkoop, et al. } \\
2008\end{array}$ & EU - 2000 & ReCiPe & $€ / \mathrm{m} 3$ \\
\hline Metal depletion & $\begin{array}{l}\text { Goedkoop, et al. } \\
2009\end{array}$ & EU - 2000 & ReCiPe & $€ /$ kg Fe eq \\
\hline $\begin{array}{l}\text { Fossil fuel } \\
\text { depletion }\end{array}$ & $\begin{array}{l}\text { Goedkoop, et al. } \\
2010\end{array}$ & EU - 2000 & ReCiPe & $€ /$ kg oil eq \\
\hline
\end{tabular}

Source: Own elaboration. 


\section{Results from the CBA}

The economic valuation of environmental impacts through the benefit transfer allow us to monetarize the environmental savings displayed by the LCA and summarized in Table 1. As shown in Table 3, promoting re-use against recycling saves $45.20 €$ in avoided environmental costs per functional unit (PC).

Results shown Table 3 also allow us to identify the categories with the highest social impact. As shown in the table above, the particulate matter formation is the category with the highest savings in social terms, reaching $16.9 €$ by PC. Reduction in human toxicity exhibits the second largest environmental savings, showing a reduction in social cost of $11.5 €$ by computer. Then, in order of economic and social importance (by PC or functional unit), fossil fuel depletion resulted in $4.43 €$ savings, climate change in $4.3 €$ while marine eutrophication exhibits $4.02 €$ of social benefit.

The relative importance of each impact category is illustrated in Figure 2. As we can see, five impact categories represent more than $90 \%$ of the total social savings from re-using a computer. In particular, particulate matter formation represents $37.2 \%$ of the total impact reduction, followed by savings in human toxicity with $25.5 \%$ of the total reduction. Only these two impacts account for $62.79 \%$ of the social benefit of re-use. Savings from fossil fuel depletion, climate change, and marine eutrophication range between $9.8 \%$ and $8.89 \%$ of the total, contributing close to $30 \%$ to the social benefit of re-use. 
Table 3: Economic valuation of environmental impacts for Spain in 2013.

\begin{tabular}{|c|c|c|c|c|}
\hline Environmental impact categories & & Units & $\begin{array}{c}\text { Unitary } \\
\text { Impact }(€)\end{array}$ & $\begin{array}{c}\text { Environmental } \\
\text { savings ( } € \text { ) }\end{array}$ \\
\hline Climate change & (kg CO2 eq) & 0,0225 & $-190,9549$ & $-4,2947$ \\
\hline Ozone depletion & (kg CFC-11 eq) & 35,1750 & $-1,82 \mathrm{E}-05$ & $-0,0006$ \\
\hline Human toxicity & (kg 1,4-DB eq) & 0,0185 & $-622,3300$ & $-11,5331$ \\
\hline Photochemical oxidant formation & (kg NMVOC) & 0,5263 & $-0,7912$ & $-0,4164$ \\
\hline Particulate matter formation & (kg PM10 eq) & 46,3302 & $-0,3637$ & $-16,8498$ \\
\hline Ionising radiation & (kg U235 eq) & 0,0382 & $-4,8189$ & $-0,1842$ \\
\hline Terrestrial acidification & (kg SO2 eq) & 0,5740 & $-1,1205$ & $-0,6431$ \\
\hline Freshwater eutrophication & (kg P eq) & 1,6022 & $-0,3865$ & $-0,6193$ \\
\hline Marine Eutrophication & (kg N eq) & 11,2452 & $-0,3575$ & $-4,0200$ \\
\hline Terrestrial ecotoxicity & (kg 1,4-DB eq) & 1,6429 & $-0,0424$ & $-0,0696$ \\
\hline Freshwater ecotoxicity & (kg 1,4-DB eq) & 0,0442 & $-9,3860$ & $-0,4152$ \\
\hline Marine ecotoxicity & (kg 1,4-DB eq) & 0,0001 & $-8,4980$ & $-0,0011$ \\
\hline Agricultural land occupation & $(\mathrm{m} 2 \mathrm{a})$ & 0,4331 & 0,3473 & 0,1504 \\
\hline Urban land occupation & $(\mathrm{m} 2 \mathrm{a})$ & 0,4331 & $-3,4745$ & $-1,5049$ \\
\hline Natural land transformation & $(\mathrm{m} 2)$ & 2,5143 & $-0,0548$ & $-0,1378$ \\
\hline Water depletion & (m3) & 0,0677 & $-2,8414$ & $-0,1924$ \\
\hline Metal depletion & (kg Fe eq) & 0,0002 & $-160,7110$ & $-0,0321$ \\
\hline Fossil fuel depletion & (kg oil eq) & 0,1019 & $-43,4950$ & $-4,4334$ \\
\hline Total environmental Impact & & & & $-45,1973$ \\
\hline
\end{tabular}

Source: Own elaboration. 


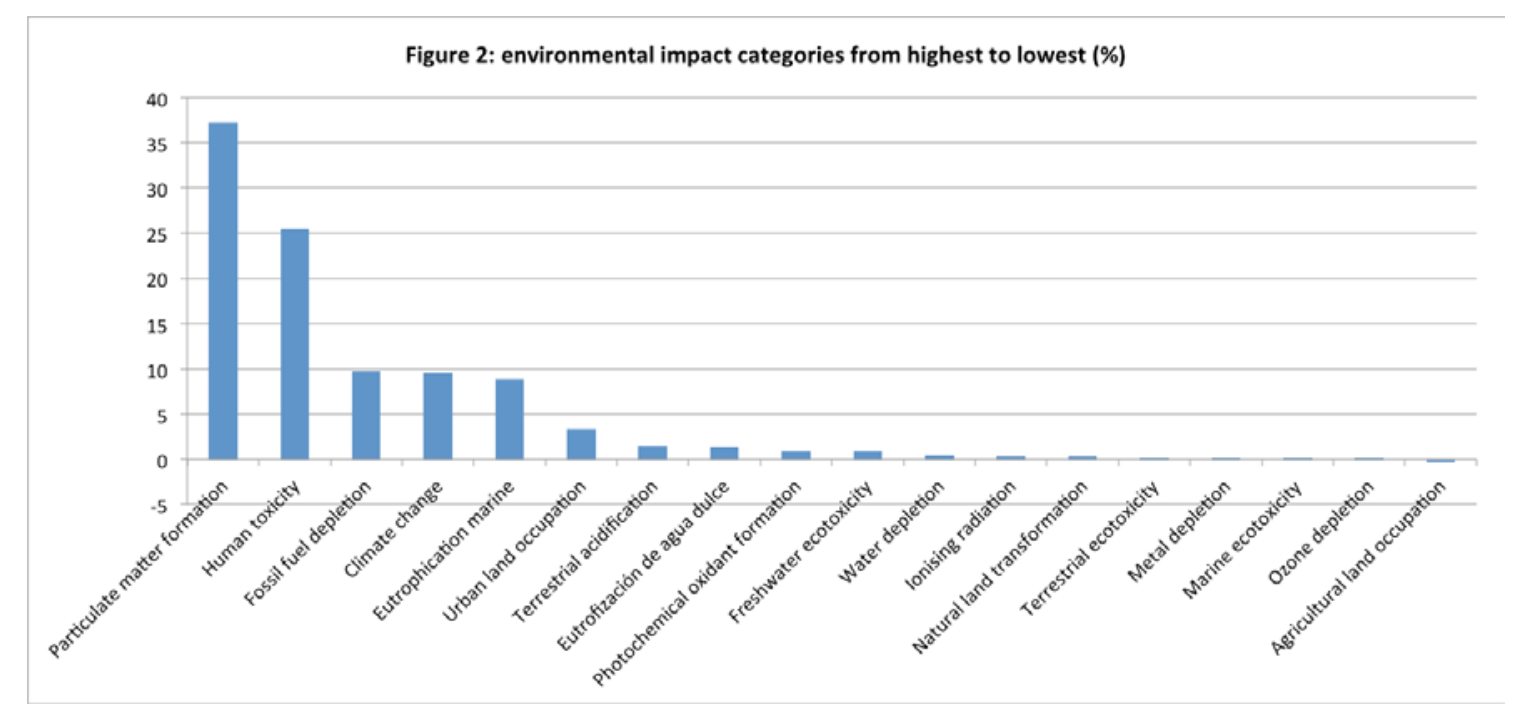

Source: Own elaboration.

It is important to emphasize that there is not a close relationship between the raking of the eighteen impact categories made by the LCA and the CBA. For instance, Figure 3 below shows that metal depletion represents the third highest impact in kg units, whereas it is one the impact categories displaying the lowest cost-benefit value. We find the opposite results for the case of particulate matter formation. The differences in the ranking of the impact categories attending to both methodologies emphasize the need to evaluate the promotion of re-use by CBA, thus going beyond effectivity analysis based only on LCA. Furthermore, CBA may provide additional benefit by providing a homogeneous measure for all impact categories (e.g., euros instead of different physical units: kg equivalent of different substances, square meters, and cubic meters). 
Figure 3: environmental impact $(\mathrm{kg})$

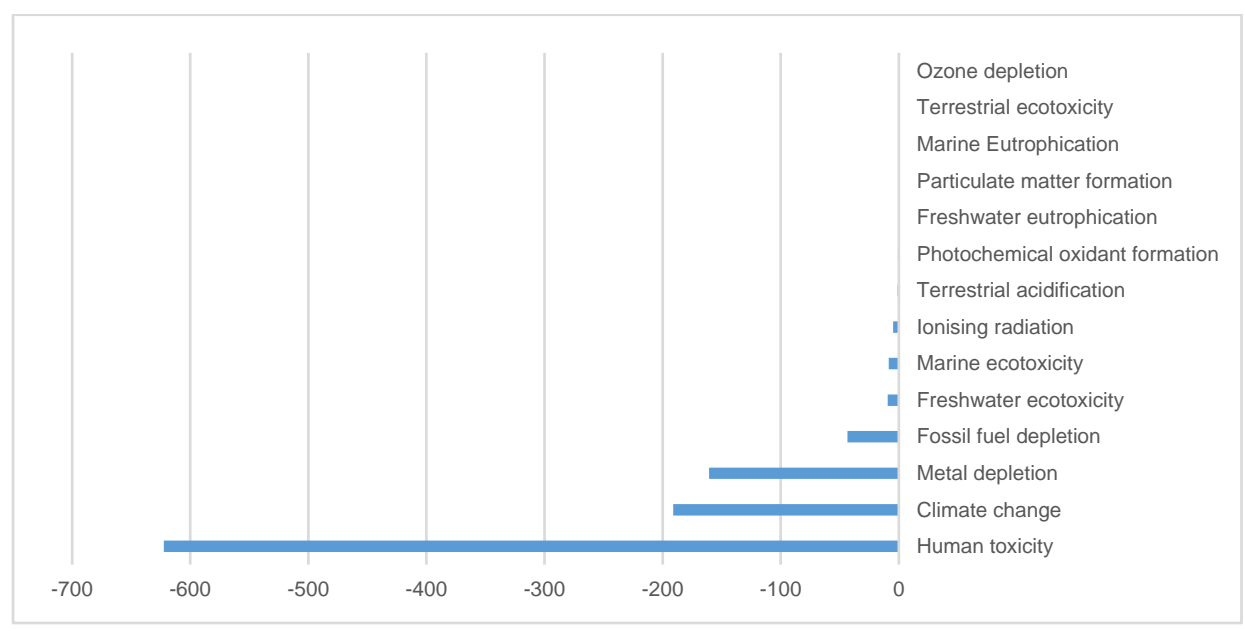

Source: Own elaboration.

\subsection{The aggregate results for the Spanish case}

The analysis in the previous section allows us to show that the promotion of re-use against recycling displays savings in environmental costs equivalent to $45.19 €$ per functional unit in Spain for 2015. However, we need additional information in order to assess the aggregated impact in Spain, such as the size of the PC market, the replacement rate, and the success rate of re-use preparation process.

Table 4. Spanish PC market (number of units).

\begin{tabular}{lcccr} 
& 2008 & 2009 & 2010 & \multicolumn{1}{c}{2011} \\
\hline PC in industrial corporation & 6.733 .721 & 7.059 .068 & 7.434 .452 & 7.524 .189 \\
& & & & \\
PC in households & 9.707 .141 & 10.822 .837 & 11.593 .162 & 12.494 .444 \\
Total number of PC & 16.440 .862 & 17.881 .905 & 19.027 .614 & 20.018 .633
\end{tabular}

Source: Own elaboration with data published by ONTSI and AMETIC.

As shown in Table 4, the stock of computers in Spain stands at about 20 million units (we did not find data later than 2011). Moreover, the LCA of the ecoRaee project was carried 
out with the assumption that the life of a new computer is equal to 5 years. This figure, transferred to the total stock of computers, means that $20 \%$ of them end their useful life each year. This assumption may be confronted with data from the Spanish market. The available data on sales shows a reduction in Spanish demand for new computers as a consequence of the economic crisis. As shown in Table 5, 3.9 million units were sold in 2011, while the stock of computers over the previous year increased by 1 million units. That means that, in 2011, 2.9 million computers were replaced, representing a replacement rate of $15 \%$ relative to the total stock $(2.9 / 19)$. Therefore, our initial assumption according to the LCA is not biased for a year without such an important economic crisis.

Table 5. Sales of central units (number of units).

\begin{tabular}{lrrrr} 
& 2008 & \multicolumn{1}{c}{2009} & \multicolumn{1}{c}{2010} & \multicolumn{1}{c}{2011} \\
\hline PC / microcomputers & 5.476 .491 & 5.021 .942 & 5.350 .377 & 3.941 .570 \\
Small systems & 6,937 & 6,299 & 6,594 & 5,689 \\
Medium systems & 298 & 261 & 236 & 148 \\
Big systems & 133 & 126 & 112 & 102 \\
\hline
\end{tabular}

Source: Own elaboration with data published by AMETIC.

The demonstrations carried out in the ecoRaee project show that the success rate in preparing equipment for re-use of the Demo IV (a general purpose computer) can reach and even exceed $80 \%$ of treated units (volume of equipment managed by the preparation process for re-use relative to equipment made available for re-use). Table 6 summarizes the success rate for each of the components of a complete PC. The high success rates of the Demo IV in the ecoRaee project are based on a business model of preparation for reuse of discarded computers by consumers who generate large volumes of WEEE and renew their equipment regularly (an example of these big consumers are large corporations). The results would be completely different as a result of promoting re-use 
among small consumers who individually generate a volume of insignificant WEEE (e.g., households, where diffuse generation of small amounts of WEEE significantly increases logistics costs), and probably with a degree of obsolescence that limits their re-use, as explained in Walther et al. (2009).

Table 6: Re-use rates.

\begin{tabular}{llll} 
& Total & Re-use & \% \\
\hline Pcs & 120 & 101 & $84 \%$ \\
Monitors & 96 & 81 & $84 \%$ \\
Keyboards & 28 & 26 & $93 \%$ \\
Mousses & 7 & 7 & $100 \%$ \\
TOTAL & 251 & 215 &
\end{tabular}

Source: ecoRaee project.

Based on these initial figures, we calculate the aggregated results for the Spanish case considering different intensities in promoting re-use. We define two scenarios: The scenario of maximum re-use where all functional units technically feasible for re-use are prepared and actually re-used, and the scenario of low re-use rates where the goal of reuse is 3\% of collected functional units, in line with the provisions of RD 110/2015, which transpose the European WEEE Directive 2012/19/EU to Spain.

Table 7: Global results for 2011.

a) maximum re-use rate

\begin{tabular}{llll}
\hline Replacement volume & 2.9 Mill. & Replacement volume & 2,9 Mill. \\
Re-use rate & $80 \%$ & Re-use rate & $3 \%$ \\
Environmental savings per unit & $45 €$ & Environmental savings per unit & $45 €$ \\
Total environmental savings & $\mathbf{1 0 4} \mathbf{M} €$ & Total environmental savings & $\mathbf{4} \mathbf{M} €$ \\
\hline
\end{tabular}

Source: own elaboration. 
As Table 7 shows, promoting re-use versus recycling generates an important social benefit in the form of avoided negative externalities. The annual amount of social benefits obtained could reach 104 million euros under the assumption that the useful life of reused computers is extended two additional years. Obviously, this figure is obtained with the most ambitious approach: all computers are replaced after 5 years (first useful life), and efficient collection and preparation for re-use processes of this amount of WEEE could produce the maximum re-use rate. We are aware that the $80 \%$ re-use rate is not a real option because the amount of WEEE involved should imply the promotion of re-use among small consumers, which renders efficiency and social benefits to the re-use scheme.

Using a more moderate approach with a 3\% reuse success rate, the annual social benefit for the Spanish case is around 4 million euros. This figure could rise to 5.4 million euros a year if we consider the general case of average duration of 5 years for equipment, therefore leading to a $20 \%$ annual renewal rate for computers. These extreme values give us the bandwidth for the social benefits of externalities avoided by promoting re-use of office equipment in Spain.

\subsection{Some additional caveats}

This CBA compares two alternative scenarios to quantify both the monetary and nonmonetary (or externalities) costs and benefits in terms of social welfare. Additionally, it is important that these costs and benefits are properly updated with a social discount rate.

In our study, we have evaluated the welfare gains of preparation for re-use processes versus recycling by only looking for avoided externalities by each functional unit in annual terms for Spain. The main advantage of this simplified analysis is that it allows 
for the circumvention of some of the classic problems of CBAs, such as the choice of the social discount rate or adjustments on market prices for the shadow price.

Obviously, this simplified approach requires making some assumptions, which even if they are plausible, it is necessary to make them explicit to correctly interpret the results. These assumptions are the following:

Assumption 1: We assume that the PCs compared in the second useful life are perfectly substitutable goods and therefore report the same utility to the consumer.

The main focus of the CBA is to compare two different products, a new and a re-used computer, providing identical specifications and performance for a "standard" user. Thus, the ecoRae research project establishes that both products are identical in terms of use and therefore perfectly interchangeable. The economic literature (see for example Varian, 2011) considers this type of good a perfect substitute because the consumer is indifferent to using either good, as long as both goods fulfil the same function and provide similar benefits.

Thus, if the only variable distinguishing a new computer from a re-used one is the monetary cost associated with purchasing and using each of them, the consumer would choose what would represent a lower cost. In the present case, the user would opt for the one delivering a lower purchasing price and electricity cost during its lifetime.

The LCA performed by the ecoRaee project allowed us to determine the difference in energy consumption between the two computers. The ecoRaee project estimates that power consumption for a re-used computer is $381.99 \mathrm{kw} / \mathrm{h}$ during the two years of its life, while the consumption of a new computer would be of $204.06 \mathrm{kw} / \mathrm{h}$ for the same period. The difference in consumption levels enables us to estimate that the higher energy efficiency of new computers will save as much as $25.8 €$ in electricity during two years 
(calculated at the average prices of electricity in Spain in January 2015). Thus, a consumer would be indifferent between buying and using a new computer during 2 years (out of 5 years of life), or one re-used with the estimated useful life of 2 years when:

$$
p_{n} \cdot(2 / 5)+c_{n} \cdot p_{\mathrm{e}}=p_{r}+c_{r} \cdot p_{\mathrm{e}}
$$

where $p_{n}$ and $p_{r}$ are the prices of a new or re-used computer, and $c_{n} \cdot p_{\text {e and }} c_{r} \cdot p_{e}$ are the energy consumption of both computers multiplied by the price of energy

Thus, $p_{n} \cdot(2 / 5)-p_{r}=25.8 €$

Therefore, we may conclude that the consumer will be indifferent between a new and a re-used computer when the price of the new computer (weighted by $2 / 5$ to homogenize the useful life of both devices) minus the price of a re-used computer (with 2 years of useful life) is equal to the difference in electricity cost associated with both computers during 2 years of use (in the present case: $25.8 €$ ). Based on this value, the consumer will buy a re-used computer if this difference in energy costs were higher than the difference in purchasing prices. Conversely, if the difference in energy cost were lower, the consumer would get more utility buying a new computer.

Therefore, assuming a cost of a new computer of $€ 359^{7}$, we can conclude that a consumer will be indifferent between buying a new computer and a re-used computer with similar features when the maximum price of the re-used is $117.8 €$. Consequently, if the price of a re-used computer exceeds this amount, consumers would opt for buying a new computer; otherwise they would opt for buying a re-used computer. After conducting an

\footnotetext{
${ }^{7}$ Price offered on Amazon in 20/04/2015 for a "all-in-one PC": 19.45 inch HD display with backlight WLED and anti-reflection. Hard Drive SATA of 500GB and $7200 \mathrm{rpm}$, SATA DVD burner and 25GB BOX free storage. RAM 4 GB with DDR3 SDRAM technology, AMD E1 6010 to 1.35 GHz. Operating System: Windows 8.1. It also includes a USB keyboard and USB optical mouse.
} 
online search (e.g., eBay and the Spanish webstore specialized in re-used PCs "pcsegundamano"), we have verified that it is possible to purchase a computer online that is similar to that used in the LCA with a one-year warranty for $70 €$ easily. Consequently, we can say that there is an important potential demand of consumers who would purchase such equipment, providing the social benefits estimated by our CBA.

Obviously, we have used a simplifying assumption by considering perfect rational economic agents that only compare monetary costs. However, the economic reality is more complex and, in general, consumption decisions are taken according to the needs, income, tastes and preferences, information, and education of consumers. We know that rational economic agents make their decisions based on opportunity cost, i.e., the combination of price, the cost of consumption, and the satisfaction derived from having a brand new product versus the alternative of a re-used computer. With this approach, the opportunity cost of each alternative can be calculated from the following expressions:

$$
\begin{aligned}
& g_{n}=p_{n}+\left(c_{n} \cdot p_{e}\right)-\theta \\
& g_{r}=p_{r}+\left(c_{r} \cdot p_{e}\right)-\varepsilon
\end{aligned}
$$

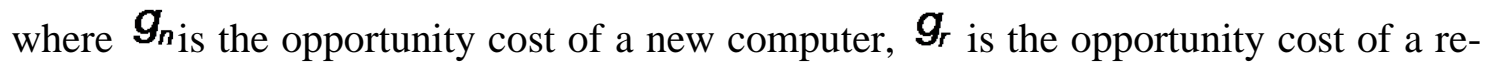
used computer, and $\boldsymbol{\varepsilon}$ is respectively the satisfaction derived from using a brand new computer and a re-used computer with less environmental cost.

Accordingly, a consumer indifferent to both products will be one who is presented with an identical opportunity cost from each alternative. Thus, by taking into account the energy consumption of each computer, the prices of electricity, the price of a new computer (prorated to homogenize the life of both devices), and a re-used computer (e.g. $70 €)$, the indifferent consumer will be the one for which the difference between the 
usefulness of a modern computer and the satisfaction of using a computer exhibiting lower environmental impacts is $37.8 €$ in 2 years:

$$
\begin{gathered}
\theta-\varepsilon=\left(p_{n}-p_{r}\right)+\left(c_{n}-c_{r}\right) \cdot p_{\mathrm{e}} \\
\theta-\varepsilon=(143,6-70)+(204,06-381,99) \cdot 0,1451=37,8 €
\end{gathered}
$$

This result allows us to figure out the areas for consumers' preferred option based on the difference between satisfaction by consumption of a new computer and satisfaction with the consumption of a re-used computer with lower environmental impact. As shown in figure 4, a consumer exhibiting high values of $\theta$ and low values of $\varepsilon$ will rate higher the availability of a new computer than the reduction of environmental impacts by using a re-used computer; therefore, she will choose a brand new computer. The opposite occurs for consumers with greater sensitivity to reduce environmental pollution than the satisfaction of using a computer with a new design.

Figure 4. Purchase decision between new and re-used computers.

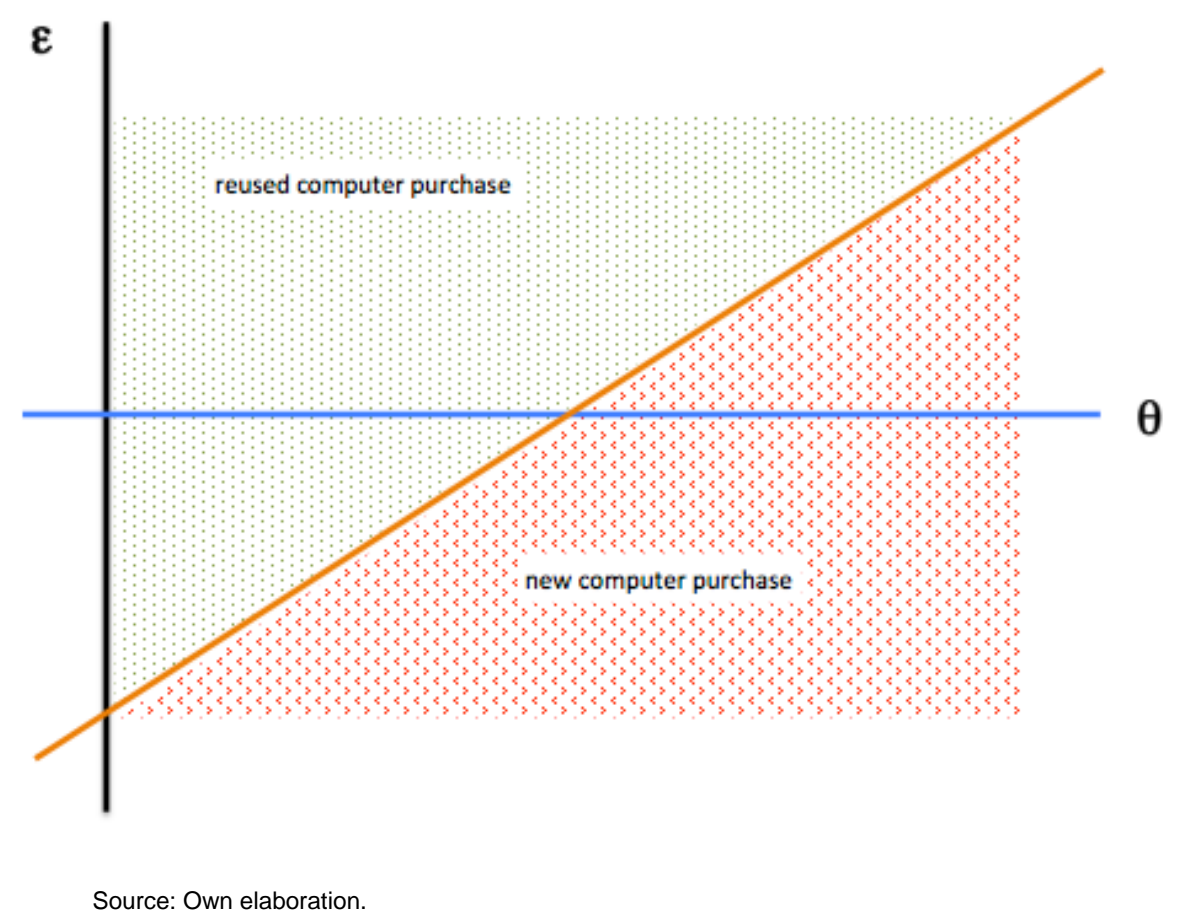


Assumption 2: We assume that changes in consumer and producer surplus from new equipment are offset by changes in consumer and producer surplus in the market of reused computers.

Unfortunately, we do not have enough information concerning the market for new computers and the market for used computers (markets evolutions, traded amounts, price elasticities, etc.). Otherwise, we could do a more accurate analysis of welfare changes (for consumers and producers) involved in the two markets. One of the expected effects of promoting re-use against recycling is the expansion of supply of re-used items and an equivalent contraction in the demand for new computers. Possibly, these changes in supply and demand would entail some changes in their prices and generate changes in the welfare of consumers and producers.

However, we can argue in this study that, for Spain, the computer market has a reduced size compared to the world market. Therefore, any eventual contraction of demand for new computers and any extra supply of re-used PCs will have a negligible impact on prices. Consequently, it is reasonable to assume that the welfare changes estimated by this CBA are mainly due to changes in the quantities exchanged in both markets (new, re-used), which offset each other. This result is particularly feasible in the scenario where the political goal for re-reused computers is $3 \%$, which represents an expansion of supply in the secondary market of 90 thousand units per year.

\section{Conclusions}

Electrical and electronic equipment have become essential elements in our lifestyles. Our dependence on devices such as computers, tablets, or mobile phones is increasing for any activity of our daily lives related to leisure or work. It is obvious that the widespread use 
of these devices has important social benefits. But the increasing accumulation of WEEE is causing serious problems that deserve our attention. Production and consumption of these goods generate a wide range of environmental impacts that are not valued or incorporated to their market prices, which is due to their intangible nature, resulting in inefficient outcomes from a social point of view.

In this study, we have evaluated the welfare gains from re-use schemes as corrective measures to reduce such externalities using CBA. Specifically, we quantified the economic impact in Spain to encourage the re-use of personal computers in accordance with the provisions of Directive 2012/19/EU of the European Parliament on WEEE. Reusing will bring down the market to what is considered socially optimal avoiding inefficient overproduction of new devices and the subsequent waste generation.

Our CBA is rooted in an LCA performed for the research project ecoRaee. It quantifies the reduction of environmental impacts by evaluating 18 impact categories in two scenarios: re-use versus recycling + new computer. The results from the LCA developed by ecoRaee confirm that re-use generates less environmental impact than the scenario recycling + new computer in all categories except one (occupation of agricultural land). This lower impact of the re-use scenario is mainly generated in the production process and distribution of new computers. Moreover, the re-use scenario is worse regarding energy consumption and the quantity of material sent to recycling. However, this underperformance is offset by lower impacts in the stages of computers production and distribution.

Through the method of benefits transfer, we have valued in monetary terms the environmental impact avoided according to the LCA. The results suggest that promoting re-use over recycling saves $45.20 €$ of environmental costs per functional unit. At the aggregate level, for the Spanish case, the extension of computers' useful life for two 
additional years and, thus replacing new equipment by re-used computers, would entail social benefits that could range from 5 to 104 million euros depending on the percentage of re-use.

These results are based on a business model of preparation for re-use of discarded computers by consumers who generate large volumes of WEEE and renew their equipment regularly. That business model for re-use activities has proved very successful. Walther et al. (2009) alerts us about the cost of promoting re-use among small consumers who individually generate a volume of insignificant RAEEs and probably with a degree of obsolescence that limits their re-use. Therefore, the upper limit to our results may be considered informative but unreal, as long as it is based on an $80 \%$ re-use rate which implies the promotion of re-use among small consumers, which renders efficiency and social benefits to the re-use scheme.

Obviously, the results should be taken with caution as they are based on the assumption that new functional units and re-used PCs are perfect substitute goods, and that may be questionable for some users, leading to an overestimation of the benefits. Moreover, the increased supply of PCs in the second-hand market could increase the size of the market (exchanges) and reduce prices, thereby shortening the technological gap. Therefore, it would generate a new demand that could be satisfied by these re-used equipment, which would increase social welfare and thereby encourage the social benefits of re-use. 


\section{References}

Andrae, A., Andersen, O. (2010). Life cycle assessments of consumer electronics-are they consistent? Int J Life Cycle Assess. The International Journal of Life Cycle Assessment 15(8), 827-836.

Babbitt, C., Kahhat, R., Williams, R., Babbitt, G. (2009). Evolution of Product Lifespan and Implications for Environmental Assessment and Management: A Case Study of Personal Computers in Higher Education. Environmental Science Technology 43, 5106-5112.

Babbitt, C., Williams, E., Kahhat, R. (2011). Institutional Disposition and Management of Endof-Life Electronics. Environmental and Science Technology 45, 5366-5372.

CE Delft. (2010). Shadow Prices Handbook: Valuation and Weighting of Emissions and Environmental Impacts.

Choi, J-K., Fthenakis, V. (2014). Crystalline silicon photovoltaic recycling planning: macro and micro perspectives. Journal of Cleaner Production 66, 443-9.

Choi, B.-C.; Shin, H.-S.; Hur, T. (2006). Life Cycle Assessment of a Personal Computer and its Effective Recycling Rate. Int. J. Life Cycle Assessment 11(2), 122-128.

Cucchiella, F., D’Adamo, I., Koh, S.L., Rosa, P. (2015). Recycling of WEEEs: an economic assessment of present and future e-waste streams. Renewable and Sustainable Energy Review 51, 263-272.

Cui, J., Forssberg, E. (2003). Mechanical recycling of waste electric and electronic equipment: a review. Journal of Hazardous Materials B 99, 243-263.

Dasgupta A.K. and Pearce, D. (1972). Cost-Benefit Analysis: Theory and Practice, Macmillan, London.

Duan, H., Eugster, M., Hischier, R., Streicher-Porte, M., Li, J. (2009). Life Cycle Assessment. Study of a Chinese Desktop Personal Computer. Science of the Total Environment 407(5), 17551764.

Goedkoop, M.J., Heijungs, R., Huijbregts, M., De Schryver, A., Struijs, J. and R. van Zelm ReCiPe (2008). A life cycle impact assessment method which comprises harmonised category indicators at the midpoint and the endpoint level, First edition (version 1.08) Report: Characterisation http://www.lcia-ReCiPe.net accessed May 2013

Hanley, N. and Spash, C. (1993). Cost-Benefit Analysis and the Environment. Edward Elgar, Cheltenham.

Hanley, N. (2001) Cost-benefit analysis and environmental policymaking Environment and Planning C: Government and Policy 19(1), 103-118.

van Harmelen, T., Korenrompa, R., van Deutekomb, C., Ligthart, T., van Leeuwenc, S., van Gijlswijk, R. (2007). The price of toxicity. Methodology for the assessment of shadow prices for human toxicity, ecotoxicity and abiotic depletion. In Quantified Eco-Efficiency (pp. 105-125). Springer Netherlands.

Hischier, R., Wäger, P.A., Gauglhofer, J. (2005). Does WEEE recycling make sense from an environmental perspective? : The environmental impacts of the Swiss take-back and recycling systems for waste electrical and electronic equipment (WEEE). Environmental Impact Assessment Review 25, 525-539. 
Hockley, N. (2014). Cost-benefit analysis: A decision-support tool or a venue for contesting ecosystem knowledge? Environment and Planning C: Government and Policy, 32(2), 283-300.

Intlekofer, K., Bras, B., Ferguson, M. (2010). Energy implications of product leasing. Environ. Sci. Technol., 44 (2010), 4409-4415.

Johansson, P.O. (1993). Cost-Benefit Analysis of Environmental Change. Cambridge University Press, Cambridge.

Kalmykova, Y., Patrício, J., Rosado, L., Berg, P. (2015). Out with the old, out with the new - The effect of transitions in TVs and monitors technology on consumption and WEEE generation in Sweden 1996-2014. Waste Management 46, 511-522.

Kissling, R., Fitzpatrick, K., Boenia, H., Luepschen, C., Andrew, S., Dickenson, J. (2012). Definition of generic re-use operating models for electrical and electronic equipment. Resources, Conservation and Recycling 65, 85-99.

Kissling, R., Coughlanb, D., Fitzpatrick, K., Boenia, H., Luepschen, C., Andrew, S., Dickenson, J. (2013). Success factors and barriers in re-use of electrical and electronic equipment. Resources, Conservation and Recycling 80, 21-31.

Kolias, K., Hahladakis, J., Gidarakos, E. (2014). Assessment of toxic metals in waste personal computers. Waste Management 34(8), 1480-1487.

Menikpura, S., Santo, A., Hotta, Y. (2014). Assessing the Climate Co-benefits from Waste Electrical and Electronic Equipment (WEEE) Recycling in Japan Journal of Cleaner Production $74,1-8$.

NEEDS (2007). Value Transfer Techniques and Expected Uncertainties NEEDS deliverable No 2.1 - RS 3a Priority 6.1: Sustainable Energy Systems and, more specifically, Sub-priority 6.1.3.2.5: Socio-economic tools and concepts for energy strategy. http://www.needsproject.org/2009/Deliverables/Needs_Rs3a_D2.1.doc

Oliveira, C., Moura, A., Gerbase. A. (2012). Collection and recycling of electronic scrap: A worldwide overview and comparison with the Brazilian situation. Waste Management 32 (2012) 1592-1610.

Ongondo, F.O., Williams, I.D., Cherrett, T.J. (2011). How are WEEE doing? A global review of the management of electrical and electronic wastes. Waste Management 31, 714-730.

Ongondo, F.O., Williams, I.D., Dietrich, J., Carroll, C. (2013). ICT reuse in socio-economic enterprises. Waste Management 33, 2600-2606

Peagam, R., McIntyre, K., Basson, L., France, C. (2013). Business-to-Business Information Technology User Practices at End of Life in the United Kingdom, Germany, and France. JOURNAL OF INDUSTRIAL ECOLOGY 17(2), 224-237,

Pearce, D., Atkinson, G., Mourato, S. (2006). Cost-Benefit Analysis and the Environment. OECD, Paris.

Sepúlveda, A., Schluep, M., Renaud, F., Streicher, M., Kuehr, R., Hagelüken, C., Gereck, A. (2010). A review of the environmental fate and effects of hazardous substances released from electrical and electronic equipments during recycling: Examples from China and India. Environmental Impact Assessment Review 30(1), 28-41.

Seyring, N., Kling, M., Weißenbacher, J., Hestin, M., Lecerf, L., Magalini, F., Khetriwal, D.S., Kuehr, R. (2015). Study on WEEE recovery targets, preparation for re-use targets and on the 
method for calculation of the recovery targets Final Report: http://ec.europa.eu/environment/waste/weee/pdf/16.\%20Final\%20report_approved.pdf

Truttmann N, Rechberger H. (2006). Contribution to resource conservation by reuse of electrical and electronic household appliances. Resources, Conservation and Recycling 48(3), 249-62.

Varian, H. (2014). Intermediate microeconomics: a modern approach. Norton (W.W.).

Walther, G., Steinborn, J., Spengler, T., Luger, T., Herrmann, C. (2009). Implementation of the WEEE-directive - economic effects and improvement potentials for reuse and recycling in Germany. The International Journal of Advanced Manufacturing Technology.

Wang, R., Xu, Z. (2014). Recycling of non-metallic fractions from waste electrical and electronic equipment (WEEE): a review. Waste Management 34(8), 1455-69.

Williams E, Kahhat R, Allenby B, Kavazanjian E, Kim J, Xu M. (2008). Environmental, social, and economic implications of global reuse and recycling of personal computers. Environmental Science and Technology 42(17), 6446-54.

Yao, M., Higgs, T., Cullen, M., Brady, T. (2010). Comparative Assessment of Life Cycle Assessment Methods Used for Personal Computers. Environmental Science \& Technology 44(19), 7335-46.

Ylä-Mella, J., Keiski, R., Pongrácz, E. (2015). Electronic waste recovery in Finland: Consumers’ perceptions towards recycling and re-use of mobile phones. Waste Management 45, 374-384

\section{Acknowledgements}

Authors acknowledge the financial support from the European Commission (Project LIFE11 ENV/ES/574). M. Rodriguez gratefully acknowledge the financial support from Spanish Ministry for Science and Education (Projects ECO2013-45706-R), and the Galician government (Projects GRC2014/021 and EM2014/044). Y. Pena-Boquete wishes to acknowledge the financial support of the Galician government, through the fellowship programe Posdoutoral B. This paper has benefited from works developed by the partners of the "ecoRaee" research project (Universidade de Vigo, Revertia and EnergyLab). Further information on this project may be available in http://www.life-ecoraee.eu/en/. 